\title{
EVALUACión DEL COSTO ANUAL EQUiVAlente DE LAS PLANTAS DE TRATAMIENTO DE AGUAS RESIDUALES DE LOS MUNICIPIOS DE CLIZA Y TOLATA
}

\author{
Gustavo Heredia, Becerra Orellana, Oliver Saavedra, Ivette Echeverría
}

\section{RESUMEN}

El objetivo de este estudio es analizar todos los costos generados por las plantas de tratamiento de aguas residuales (PTAR) de los Municipios de Cliza y Tolata, en la región del Valle Alto de Cochabamba. El estudio utiliza la metodología denominada Costo Anual Equivalente (CAE) con la intención de determinar no solamente los costos de inversión de la planta, sino también todos los costos relacionados con la operación y mantenimiento de la planta en el tiempo. Las PTAR de Cliza y Tolata tienen 10.000 y 3.200 beneficiarios respectivamente. El costo total de inversión de la PTAR Cliza es de 533.950 USD. El costo anual equivalente de esta PTAR utilizando una tasa de descuento del 5\% es de 60.591 USD/año. De este monto, el 68\% (41.179 USD/año) corresponde al CAPEX y el $32 \%$ (19.412 USD/año)) corresponde al OPEX. El costo total per cápita es de 6,06 USD/cápita por año y el costo total por $\mathrm{m}^{3}$ de agua tratada es de $0,29 \mathrm{USD} / \mathrm{m}^{3}$. El costo total de inversión de la PTAR de Tolata es de 254.524 USD. El costo anual equivalente de esta PTAR utilizando una tasa de descuento del 5\% es de 51.541 USD/año. De este monto, un $66 \%$ (34.048 USD/año) y un $34 \%$ (17.493 USD/año) corresponden al CAPEX y OPEX respectivamente. El costo total per cápita es de 16,11 USD/cápita por año y el costo total por $\mathrm{m}^{3}$ de agua tratada es de $0,40 \mathrm{USD} / \mathrm{m}^{3}$. Es evidente que los costos de Operación y Mantenimiento $(\mathrm{O} \& \mathrm{M})$ son significativos y esto confirma la importancia de contar con una estrategia que garantice la sostenibilidad financiera del servicio en el tiempo. En particular la tecnología UASB de las PTARs Cliza y Tolata tiene bajo consumo de energía por tanto sus OPEX son más bajos que otras tecnologías convencionales. Recomendamos estimar el costo anual equivalente y registrar todos los costos anuales involucrados en la operación de las PTAR. La estimación de los costos utilizando los métodos descritos en este estudio ayudará a hacer comparaciones apropiadas entre las tecnologías y, finalmente, a tomar mejores decisiones en la planificación e implementación de futuros sistemas de tratamiento.

Palabras Clave: Costo Anual Equivalente, OPEX, CAPEX, Cliza, Tolata, PTAR.

DOI: 10.23881/idupbo.019.2-5e 